\title{
Flume-Scale Testing of an Adaptive Pitch Marine Hydrokinetic Turbine
}

\author{
Ramona B. Barber ${ }^{a}$, Craig S. Hill ${ }^{\mathrm{b}}$, Pavel F. Babuska ${ }^{\mathrm{a}}$, Richard Wiebe ${ }^{\mathrm{a}}$, \\ Alberto Aliseda ${ }^{\mathrm{b}}$, Michael R. Motley ${ }^{\mathrm{a}}$ \\ ${ }^{a}$ Department of Civil \& Environmental Engineering, \\ University of Washington, Seattle, WA \\ ${ }^{b}$ Department of Mechanical Engineering, University of Washington, Seattle, WA
}

\begin{abstract}
Modern marine hydrokinetic turbine blades are typically constructed from fiber reinforced polymer (FRP) composites, which provide superior strengthand stiffness-to-weight ratios and improved fatigue and corrosion resistance compared to traditional metallic alloys. Furthermore, numerical studies have demonstrated the possibility of tailoring the anisotropic properties of FRP composites to create an adaptive pitch mechanism that can improve system performance, especially in off-design or varying flow conditions. Potential benefits of an adaptive pitch system include increased lifetime energy capture, reduced hydro-elastic instabilities, reduced risk of mechanical failure, and improved efficiency, load shedding, fatigue life, and structural integrity. In this work, static and dynamic testing results for a flume-scale marine hydrokinetic turbine system are presented. Two sets of adaptive composite blades are compared to neutral pitch composite and rigid aluminum designs. Static testing was used to quantify the mechanical load-deformation response
\end{abstract}

Email address: rbbarber@uw.edu (Ramona B. Barber) 
of each blade type. Additionally, instantaneous blade and full system loading was measured during dynamic flume testing, allowing a multilevel analysis of adaptive blade performance. Experimental results show notable shifts in the power and thrust coefficients and significant load adjustments induced through passive pitch adaptation, suggesting that adaptive pitch composite blades could be a valuable addition to marine hydrokinetic turbine technology.

Keywords: Marine renewable energy, tidal turbines, adaptive composites, bend-twist coupling

\section{Introduction}

Marine hydrokinetic turbines are typically deployed in dynamic, energydense locations and are subject to complex spatially and temporally varying flow. To withstand the associated loads and survive in the harsh offshore environment, marine turbine blades are increasingly constructed from fiber reinforced polymer (FRP) composites, which provide superior strength- and stiffness-to-weight ratios and improved fatigue and corrosion resistance compared to traditional metallic alloys. Furthermore, numerical studies have demonstrated the possibility of tailoring the anisotropic properties of FRP composites to improve system performance, especially in off-design or varying flow conditions [1-6]. Through proper design, the intrinsic bend-twist deformation coupling behavior of anisotropic composites can be utilized to develop a passively adaptive pitch mechanism, where elastic deformations vary dynamically with loading condition. Potential benefits of an adaptive pitch system include increased lifetime energy capture, reduced hydro-elastic 
instabilities, reduced risk of mechanical failure, and improved efficiency, load shedding, fatigue life, and structural integrity $[1,3,7]$.

In marine and ocean engineering, experimental investigations into passive pitch adjustment have until now focused mostly on propulsion systems. In [8-10], it was determined that flexible composite propellers could be tailored to be more efficient over a wider range of speeds when compared to traditional metallic alloy blades. In [11] and [12], the effects of material anisotropy in marine propellers in steady and unsteady flow environments were examined. Numerical and experimental results showed that adaptive composite propellers can provide improved cavitation performance and increased energy efficiency over their rigid counterparts when operating at off-design conditions or in spatially varying flows.

While the use of adaptive pitch blades for marine hydrokinetic turbines has been thoroughly explored numerically, little experimental work has been published to date. In [13], isotropic flexible blades were tested for use on an axial turbine in an oscillating water column device. The study compared a rigid urethane blade to two urethane blades with higher flexibility. However, the material used was isotropic, meaning it was not possible to tailor the twisting deformation of the blades. The results indicated that the flexible blades operated at a higher efficiency than the rigid blade, especially at low flow or off-design conditions. In a more complete experimental program, [14-16] outline the testing regime of the full scale variable speed, fixed pitch horizontal axis turbine developed by the company SCHOTTEL. The composite turbine blades presented were designed to be passively adaptive in order to reduce loading in overspeed conditions, and were shown to reduce thrust 
by approximately $50 \%$ compared to a rigid blade design in overspeed conditions. However, little detail is provided concerning the proprietary geometry of the blades; the results are therefore difficult to use or reproduce.

In order to validate and support continuing numerical studies of adaptive blades, it is necessary to provide baseline experimental data on these systems. To that end, this work presents the results of a series of static and dynamic tests carried out on a flume-scale adaptive pitch turbine system. An experimental program was conducted to investigate the mechanics of adaptive pitch blades and the impact these blades have on the performance of a marine turbine system. The performance of two sets of adaptive composite blades were compared to that of a neutral pitch blade design and an effectively rigid aluminum set. This program was designed to expand the numerical work and conclusions presented in [1].

The experimental regime was conducted in two parts. In a static testing environment, bend-twist load deformation characteristics of each set of blades were obtained. Force-deflection and force-twist response were measured, and an empirical deflection-twist relationship was calculated. In corresponding dynamic flume tests, instantaneous forces and moments on the entire rotor and on one of the three blades were recorded during operation over a range of tip speed ratios. Each test was repeated at varying inflow velocity conditions. These data were used to calculate blade forces and moments as a function of tip speed ratio, as well as overall system performance curves at several inflow velocities. Trends in performance results showed good agreement with those published in previous numerical studies, including notable shifts in the power and thrust coefficients and significant load adjustments induced 
through passive pitch adaptation.

\section{Blade Design and Fabrication}

All blades discussed in this work were designed to identical geometric parameters; the tailored bend-twist mechanism in the adaptive models was created solely on the material level. The blade geometry was determined using an optimization routine in HARP_Opt (Horizontal Axis Rotor Performance Optimization) code developed by the National Renewable Energy Laboratory (NREL). HARP_Opt implements the WT_Perf Blade Element Momentum (BEM) theory to predict rotor performance while iteratively optimizing the hydrodynamic shape of the blade chord lengths, twist, and thickness distributions. Primary input for HARP_Opt includes a distribution of design current velocities and aerodynamic coefficients for the desired blade profiles (i.e. lift, drag, pitching moment, and minimum pressure coefficients). In this case, the system was designed to operate in conditions typical to Puget Sound, WA, as outlined in $[1,17]$. As a result, the blade section profiles transition from a circular root at the hub radius $\left(d_{H} / 2=0.055 \mathrm{~m}\right)$ through a series of NACA-44xx profiles to the tip of the blade $\left(d_{T} / 2=0.225 \mathrm{~m}\right)$. The blades were aligned at a resting position of $0^{\circ}$ pitch (i.e. $2.97^{\circ}$ pre-twist at the tip). The NACA-44 series was chosen because it has been used extensively for marine hydrodynamic turbines due to the benefits of low critical Reynolds number for transition from laminar separation bubble, high lift to drag ratio, large structural rigidity, and acceptable cavitation resistance. See Table 1 for full details of the geometry. 


\begin{tabular}{cccc}
$r / R$ & $c / r$ & $t / c$ & Pre-Twist $\left(^{\circ}\right)$ \\
\hline 0.23 & 0.35 & 1.00 & 15.40 \\
0.24 & 0.34 & 1.00 & 15.40 \\
0.25 & 0.36 & 0.93 & 15.40 \\
0.26 & 0.42 & 0.86 & 15.40 \\
0.27 & 0.53 & 0.54 & 15.40 \\
0.29 & 0.66 & 0.39 & 15.40 \\
0.30 & 0.66 & 0.28 & 15.40 \\
0.32 & 0.64 & 0.24 & 15.40 \\
0.35 & 0.57 & 0.23 & 15.27 \\
0.39 & 0.49 & 0.21 & 12.63 \\
0.43 & 0.42 & 0.20 & 10.73 \\
0.47 & 0.35 & 0.19 & 9.36 \\
0.51 & 0.29 & 0.18 & 8.34 \\
0.56 & 0.25 & 0.17 & 7.55 \\
0.60 & 0.21 & 0.17 & 6.92 \\
0.64 & 0.18 & 0.16 & 6.39 \\
0.69 & 0.16 & 0.15 & 5.93 \\
0.73 & 0.15 & 0.15 & 5.51 \\
0.77 & 0.14 & 0.15 & 5.12 \\
0.81 & 0.13 & 0.15 & 4.77 \\
0.84 & 0.12 & 0.15 & 4.44 \\
0.87 & 0.12 & 0.15 & 4.14 \\
0.90 & 0.11 & 0.15 & 3.86 \\
0.93 & 0.11 & 0.15 & 3.62 \\
& & \\
0.53
\end{tabular}




\begin{tabular}{lrllc} 
& 0.95 & 0.11 & 0.15 & 3.41 \\
& 0.97 & 0.10 & 0.15 & 3.23 \\
& 0.98 & 0.10 & 0.15 & 3.10 \\
& 0.99 & 0.10 & 0.15 & 3.01 \\
& 1.00 & 0.10 & 0.15 & 2.97 \\
Table 1: & Blade geometry characteristics, NACA-44xx \\
profiles. & \multicolumn{4}{l}{}
\end{tabular}

The bend-twist coupling mechanism that creates an adaptive composite blade is a function of material design. In general terms, the anisotropic nature of the composite fibers in the blade define a material strong axis that can be rotationally offset from the longitudinal axis of the blade by a specified amount. This creates an elastic load-dependent deformation mechanism in which an applied shear load, for example, will result in twisting as well as bending deformations even in the absence of a torsional load. The degree of coupling between the bending and twisting deformations can be controlled by the magnitude of the offset angle, while the direction of offset determines the direction of blade twist. With this strategy, blades can be designed to either increase or decrease pitch angle under load. Because the magnitude of the deformation is load-dependent, it is possible to design a blade that will adapt to changing flow conditions via a nearly instantaneous structural response. Further detail on this subject can be found in $[1,2,12]$.

To fully explore the adaptive pitch effect, two sets of adaptive composite blades were compared to a non-adaptive composite set and a set of aluminum blades. One set of adaptive blades was tailored with a pitch to stall bias, such 
that an increased fluid loading would cause each blade to twist towards stall, decreasing the pitch angle and increasing the effective angle of attack. The other set of adaptive blades was designed to behave in the opposite fashion, pitching to feather and increasing the pitch angle (thus decreasing the angle of attack) under load. The non-adaptive, or neutral, composite blades provided a baseline with identical composite fabrication but no material bend-twist coupling. The aluminum set was assumed to be effectively rigid, allowing further comparison between rigid and flexible blades.

Due to the small scale of the blades required for flume-level testing, it was not feasible to lay up an adaptive composite laminate following the complex blade geometry with sufficient accuracy in either the geometry or the fiber orientation. To address this issue, the composite blades were composed of a flat carbon fiber spar, twisted to follow the chord line of the target blade geometry, and a semi-flexible urethane body cast around the spar to create the hydrodynamic blade shape. The urethane was chosen such that it had adequate hardness to maintain the blade geometry but would not significantly impede the elastic bend-twist deformations. In this way, the adaptive tailoring of the composites could be explicitly controlled in the carbon fiber spar without sacrificing accuracy in the hydrodynamic profile. This fabrication process was used solely for the small-scale blades in this initial test sequence; future work on larger scales will use more traditional manufacturing processes.

To design the appropriate composite laminate spars for the adaptive blades, a parametric study in ABAQUS/Standard [18] was conducted. A target pitch change $\left( \pm 5^{\circ}\right)$ and a limit on bending deflection (10\% of the 
blade length) at the design condition were imposed, along with constraints based on the predefined geometry. To design for both twist and deflection, the thickness and fiber angle of the laminate were tailored. Varying the fiber angles of the laminate resulted in an "unbalanced" laminate and induced bend-twist coupling, while laminate thickness was adjusted to meet target deflection goals. The resulting laminates each consisted of 14 plies of unidirectional IM7/8552 Hexply carbon fiber, resulting in a final spar thickness of $1.43 \mathrm{~mm}$. All plies for the adaptive blades were laid up with a $7^{\circ}$ fiber angle offset from the blade axis: $+7^{\circ}$ for the pitch to feather blades and $-7^{\circ}$ for the pitch to stall blades. The neutral composite blades were also 14 ply, with the unidirectional fibers aligned with the blade longitudinal axis. Though the coupling between bending and twisting behaviors has been shown to reach a maximum with fiber angles of $\approx 30^{\circ}$, the bending stiffness of composite laminates reduces drastically with fiber angles greater than $10^{\circ}$. With a higher degree of bend-twist coupling, the thickness required of the laminate to limit tip bending deflections would have been greatly increased. Because the thickness of the composite spar was limited by the geometric parameters, less coupling was chosen in order to maintain adequate bending stiffness. The fiber angle offset required for the creation of an adaptive mechanism will always result in reduced stiffness compared to a neutral fiber orientation, however all deflections were within the acceptable range. Properties of all three materials used are shown in Table 2. 


\begin{tabular}{|c|c|}
\hline Aluminum & $\begin{array}{l}\text { Compound: } 6061-\mathrm{T} 6 \\
\begin{array}{c}\rho=2700 \mathrm{~kg} / \mathrm{m}^{3} \\
E=68.9 \mathrm{GPa} \\
G=26 \mathrm{GPa} \\
\nu=0.33\end{array}\end{array}$ \\
\hline $\begin{array}{c}\text { Carbon Fiber } \\
\text { Laminate }\end{array}$ & $\begin{array}{c}\text { Compound: Hexcel IM7 } / 8552 \\
\rho=1570 \mathrm{~kg} / \mathrm{m}^{3} \\
E_{1}=158 \mathrm{GPa}, E_{2}=E_{3}=8.96 \mathrm{GPa} \\
G_{12}=G_{13}=4.69 \mathrm{GPa}, G_{23}=3.09 \mathrm{GPa} \\
\nu_{12}=\nu_{13}=0.316, \nu_{23}=0.451\end{array}$ \\
\hline Urethane & $\begin{array}{l}\text { Compound: Smooth-Cast 45D } \\
\qquad \rho=1100 \mathrm{~kg} / \mathrm{m}^{3} \\
\text { Shore Hardness: } 45 \mathrm{D} \\
\text { Elongation at Break: } 100 \%\end{array}$ \\
\hline
\end{tabular}

Table 2: Blade material properties

\section{Experimental Methodology}

\subsection{Turbine Instrumentation}

The three-bladed variable-speed, fixed-pitch axial-flow turbine (rotor diameter, $d_{T}=0.45 \mathrm{~m}$ ) used during these experiments is shown in Figs. 1 and 2. An Applied Motion ST10-Q-RE motor drive controlled a Parker Automation LV233 stepper motor inside of the nacelle to apply a user-defined continuous and constant rotor angular velocity. Blade angular position was measured using an Applied Motion ZAA optical encoder mounted on the main drive shaft. Two load cells were used to measure forces and moments 
on the system. A six-axis ATI Industrial Automation Mini45 load cell provided the connection between the main drive shaft and the hub, enabling instantaneous measurements of rotor loads and moments used to calculate performance characteristics. Inside the rotating hub, a six-axis ATI Industrial Automation Nano25 load cell was mounted to the root of one of the three blades (from here on referred to as the "key blade") to acquire instantaneous measurements of the blade loads and moments. The coordinate systems associated with each load cell are diagrammed in Figure 3. During flume testing, a Nortek Vector acoustic Doppler velocimeter (ADV) was positioned approximately $1.1 \mathrm{~m}\left(\approx 2.5 d_{T}\right)$ upstream of the turbine. The ADV sampled instantaneous three-dimensional inflow velocities.

\subsection{Experimental Facility and Procedures}

Load-deformation testing on the turbine was performed in the structural vibrations laboratory at the University of Washington. The blades were loaded quasi-statically in the streamwise direction (see Fig. 3; negative $B F_{Y}$ direction) using a displacement-controlled method in which a slowly incrementing displacement was applied to the blade tip at the neutral pitch axis. The force-displacement test was repeated three times for each individual blade, and displacement data was used from the loading period only to avoid capturing any hysteretic behavior in the unloading period. Two lasers, a Micro-Epsilon optoNCDT 2300-20 and a Micro-Epsilon optoNCDT 1700500 , were used to measure deflection of the blades under load. The lasers each captured "streamwise" deflection $163 \mathrm{~mm}$ from the blade root $(r / R=$ 0.96) at points separated by $14.7 \mathrm{~mm}$ along the chord of the blade, as depicted 

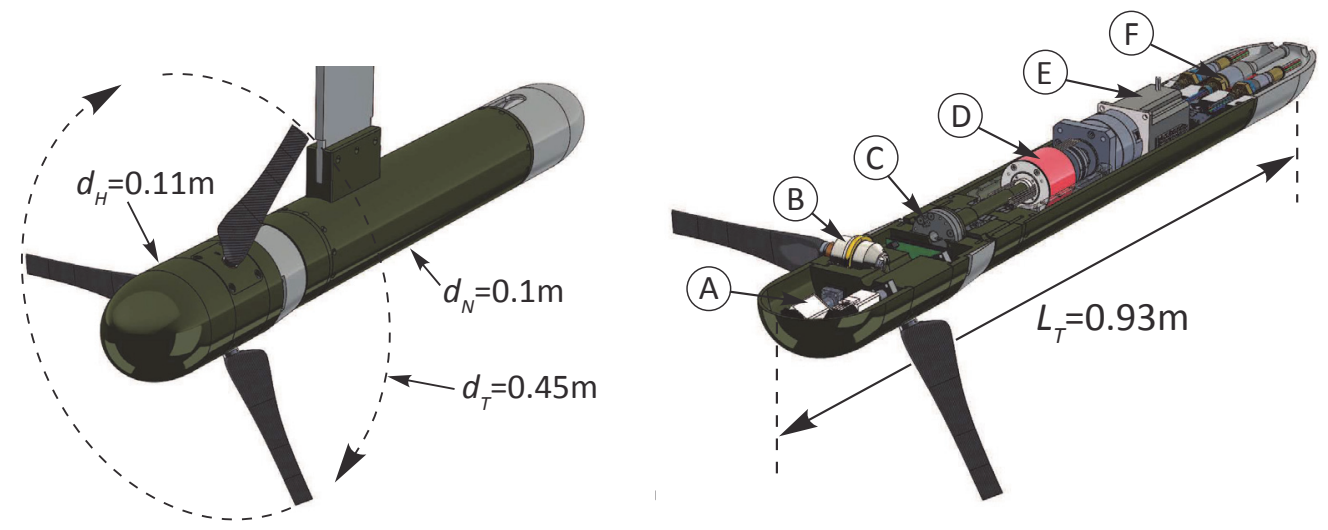

(a) Schematic of the axial flow turbine (b) Internal schematic of the turbine: (A) Acshowing rotor diameter, $d_{T}$, hub diameter, tive blade pitch control motors; (B) Six-axis $d_{H}$, and nacelle diameter, $d_{N}$. blade root load cell; (C) Six-axis hub load cell; (D) Slip ring; (E) Rotor speed control motor and encoder; and (F) Communication and data acquisition cables connections.

Figure 1: Turbine schematics.

in Fig. 4. Each individual blade was mounted on the key blade load cell of the turbine for the test, which was used to record forces and moments corresponding to the applied displacement. Measurements from the two lasers and the load cell were synchronized in order to calculate force-deflection, force-twist, and deflection-twist relationships.

In addition to the static test program, dynamic experiments were conducted at the Bamfield Marine Sciences Center in Bamfield, BC, Canada. The Bamfield facility includes a recirculating rectangular open channel flume ( $b=0.98 \mathrm{~m}, L=13 \mathrm{~m})$. Fluid velocity in the flume is controlled by a series of four pumps, allowing for speeds of up to $1.0 \mathrm{~m} / \mathrm{s}$. The dynamic water 


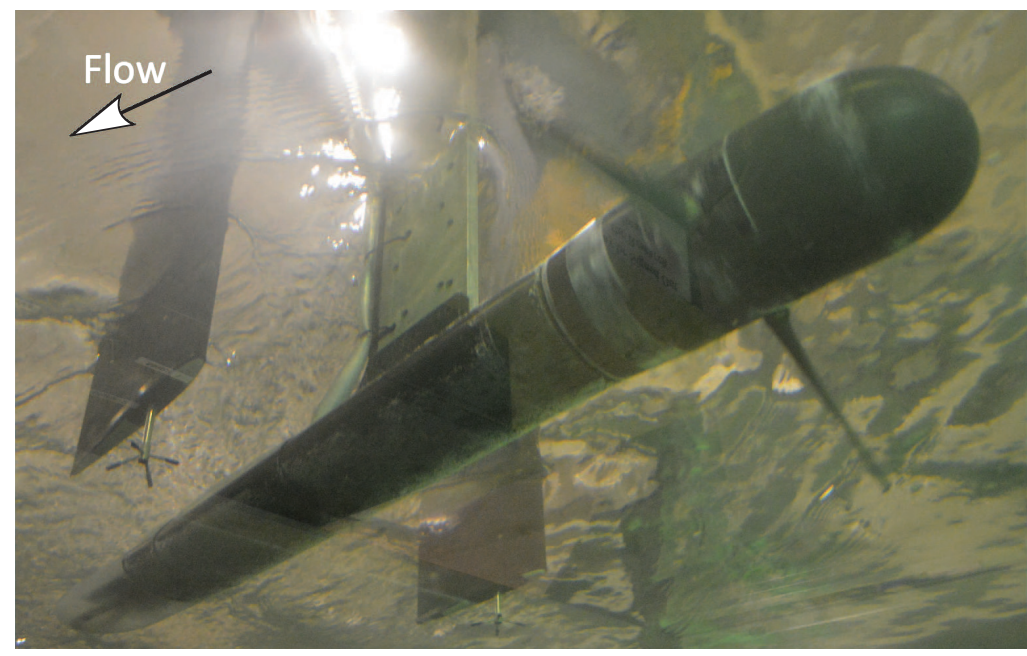

Figure 2: Photo of the axial flow turbine operating during experiments.

depth and temperature were held constant at $h_{d}=0.73 \mathrm{~m}$ and $T=16^{\circ} \mathrm{C}$, respectively, for all tests. The level of turbulence in the flume was around 7-8\%, consistent with field measurements in Puget Sound and previous flume experiments in the literature [17]. The turbine was placed near the center of the flume longitudinally, with the hub height, $h_{h u b}=0.375 \mathrm{~m}$, set to approximately half of the static water depth in the flume. Performance curves were generated by holding the fluid velocity constant and increasing turbine rotational speed, in order to measure loads over a range of tip speed ratios. Measurements at each point on the performance curve were sampled at $\approx$ $16 \mathrm{~Hz}$ for 2-5 minutes to ensure steady state operation. Due to the loaddependent nature of the adaptive blades, however, performance is dependent on both velocity and tip speed ratio. Therefore, curves were collected for the adaptive pitch blades at three inflow velocities: $U_{h u b}=0.5 \mathrm{~m} / \mathrm{s}, 0.65 \mathrm{~m} / \mathrm{s}$, and $0.85 \mathrm{~m} / \mathrm{s}$, resulting in a range of Reynolds numbers $R e_{D}=2.0-3.4 x 10^{5}$ 


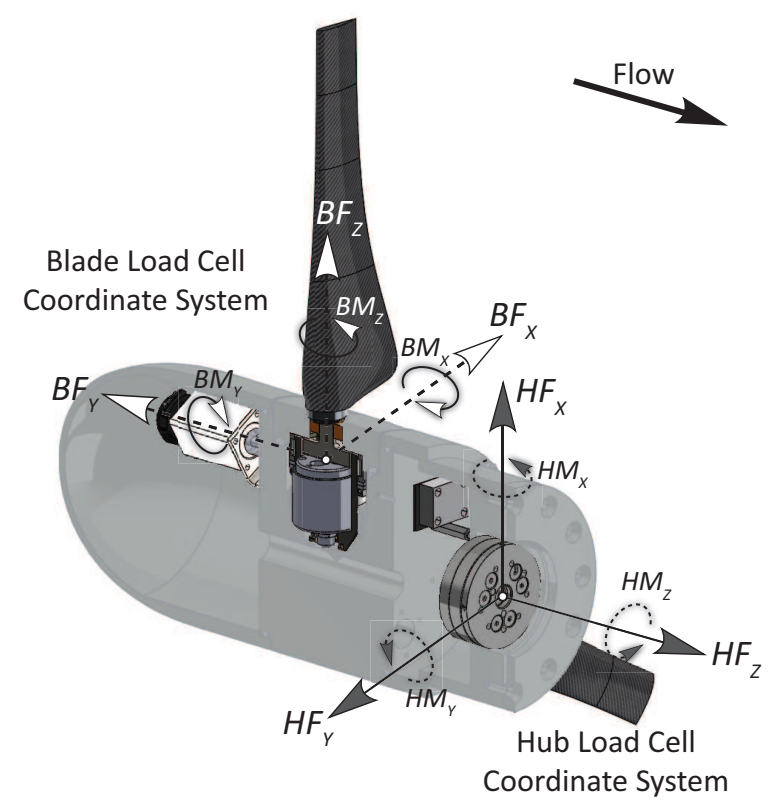

Figure 3: Schematic of the blade $\left(B F_{x y z}, B M_{x y z}\right)$ and hub $\left(H F_{x y z}, H M_{x y z}\right)$ load cell coordinate systems.

$\left(R e_{c} \approx 0.7-1.1 x 10^{5}\right)$. For comparison with the composite blades and to investigate effects of Reynolds number dependence, performance curves for the rigid aluminum blades were collected at $U_{h u b}=0.5 \mathrm{~m} / \mathrm{s}, 0.85 \mathrm{~m} / \mathrm{s}$, and 1.0 $\mathrm{m} / \mathrm{s}$.

\section{Results}

As with any experiment, possible error from several sources contribute to varying amounts of uncertainty in the results. However, this work is primarily a comparative study between the behavior of geometrically identical blades under the same hydrodynamic conditions; the results presented herein are not intended to provide an accurate prediction of full scale turbine performance 


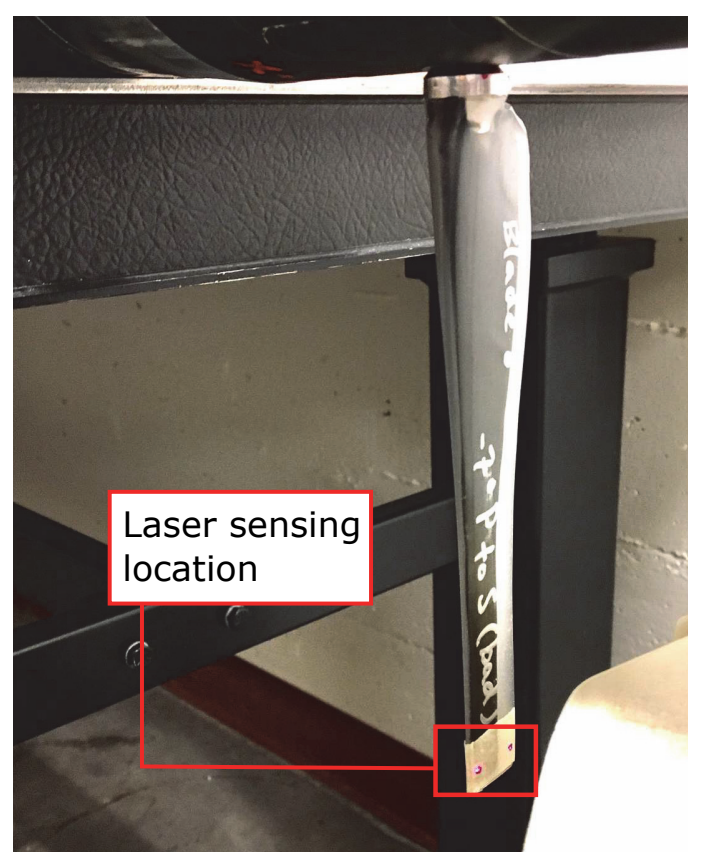

Figure 4: Placement of laser sensors on turbine blade for load-deformation tests.

and loads in a realistic deployment. Therefore, an in-depth discussion of uncertainty is not included. The uncertainty of the data collected during these experiments, including both random and systematic uncertainties, was analyzed following methods outlined in ASME PTC 19.1-2005 [19]. The results are shown in confidence intervals on calculations where several sources of uncertainty combine, such as in the non-dimensionalized coefficients of power and thrust. The uncertainties were otherwise found to be negligible for the purposes of this work.

\subsection{Static Load-Deformation Tests}

Static load-deformation tests were conducted in order to quantify the force-deformation relationships of all four blade sets in response to a single 
point load. Though in practice the loading profile on a turbine blade is highly complex, these tests provide a baseline performance survey to both confirm design behavior and calibrate future numerical models. Note that because the deformation in each test was applied at the blade tip and the deflections were measured at $r / R=0.96$, simple beam theory was used to extrapolate the deflection and twisting responses to the tip. This was determined to be an acceptable approximation due to the small deflections and curvatures.

Figures 5(a) and 5(b) show the results of a suite of force-deformation tests. Point data from each of three tests conducted on every blade is reported. In Fig. 5(a), the strongly linear nature of the force-deflection response is clear. However, nonlinear behavior is apparent in deflections under $1 \mathrm{~mm}$; this is likely due to a slight amount of play in the blade root-to-hub fitting. As expected, the aluminum blades display a nearly rigid behavior, showing maximum deflections on the order of $10 \%$ of those measured in the adaptive blades. The adaptive composite blades behave similarly to the neutral design; however, the reduced stiffness that is a function of the adaptive mechanism can clearly be seen. The bending deformation of the pitch to feather and pitch to stall blades is effectively identical. This is to be expected, as the fiber angle offset, and thus stiffness reduction, is the same magnitude in the two blades designs.

The difference in the direction of the fiber angle offset can be seen in the force-twist response, shown in Fig. 5(b). Though the adaptive blades display very similar behavior in bending, the force-twist responses in the two designs are opposite. The pitch to feather blades show a positive pitch change, while the pitch to stall blades twist in a negative direction. Again, the aluminum 
blades display effectively rigid behavior, while the neutral composite shows a slight bias towards pitching to feather (increasing pitch). The trends in these results are also linear, though the correlation is less strong than in the force-deflection responses. The scatter in Fig. 5(b) is due to the difficulty in imposing a displacement on the blade tip without influencing the twisting deformations. Though the blades were loaded at a point as close to the neutral pitch axis as possible, any small deviation from that point will have a significant impact on the twist response. 


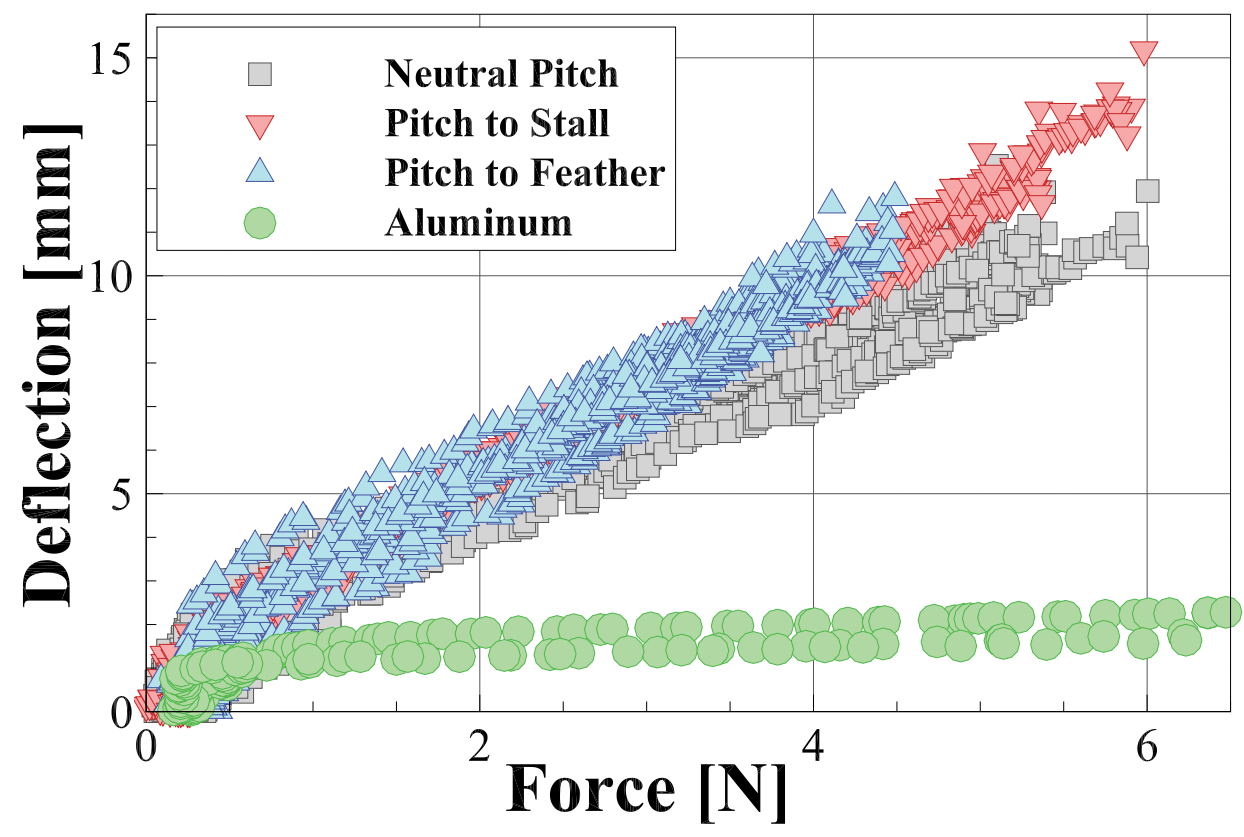

(a) Force-deflection response at blade tip.

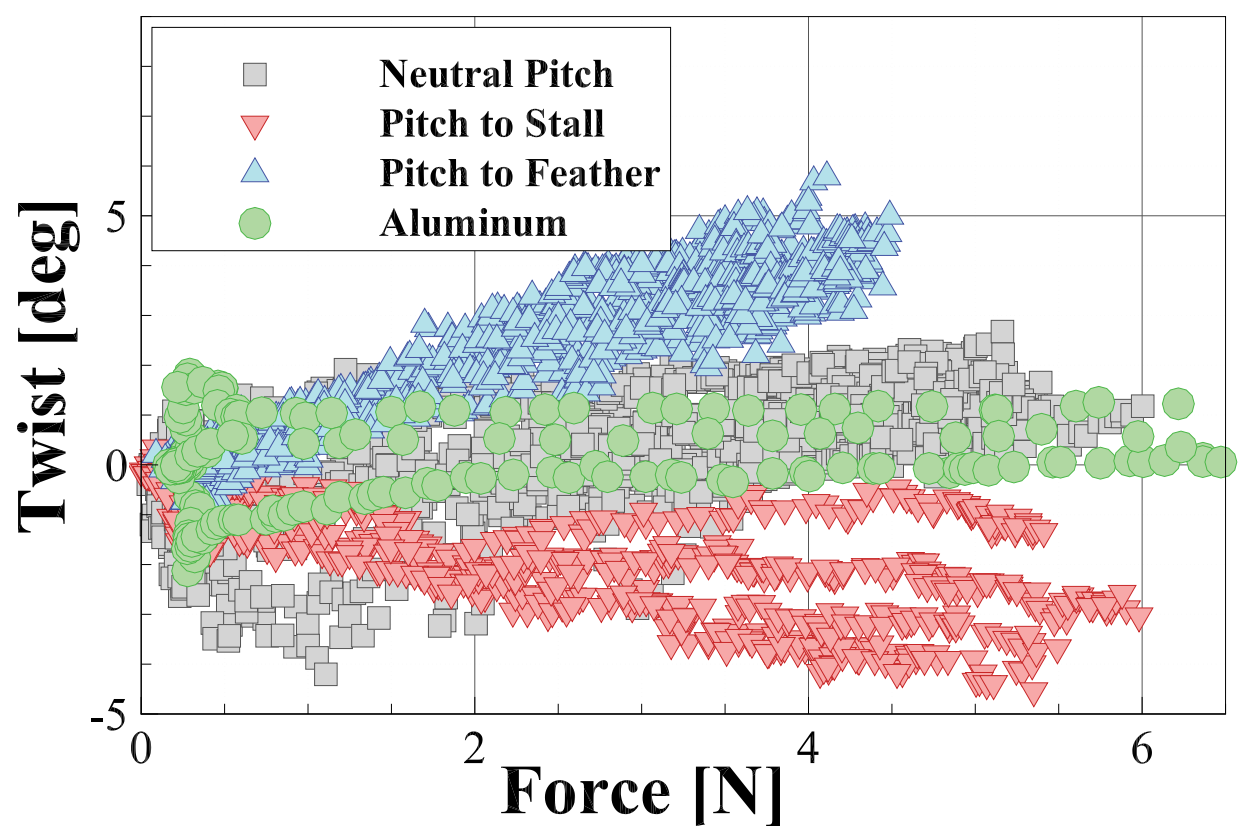

(b) Force-twist response at blade tip.

Figure 5: Load-dependent elastic defb8mation responses of each blade type. 
The deflection and pitch change responses are combined in Fig. 6 to show empirical bend-twist relationships. A linear regression for each blade design is plotted for additional clarity. As expected, the bend-twist response of the pitch to feather blades is approximately equal in magnitude (as measured from the neutral pitch behavior) and opposite in direction to that of the pitch to stall blades. Though the aluminum blades displayed effectively rigid behavior by neither bending nor twisting to a significant extent, they show the same influence of the slight geometric bias to pitch to feather as the neutral composite blades, a behavior that agrees with previous numerical predictions $[1,2]$. However, the correlation of the aluminum bend-twist response especially is quite low, and additional tests are necessary for conclusive results. 


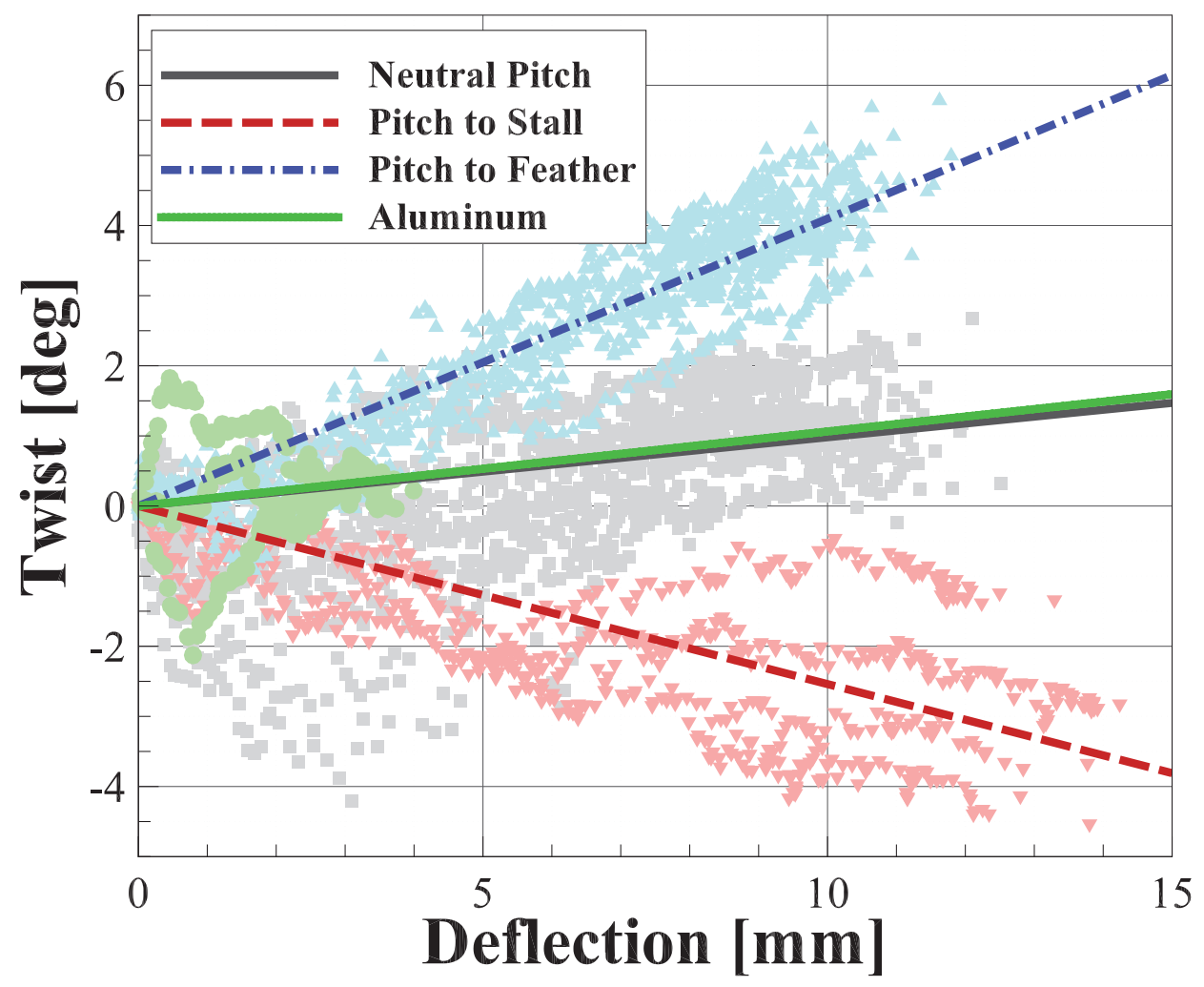

Figure 6: Deflection-twist relationship, with linear regression plotted.

In general, the results of the load-deformation tests showed good agreement with design goals and behavior predictions stated in Section 2. The pitch to feather blades displayed a bias to increase blade pitch under load, while the pitch to stall design tended to decrease blade pitch. Both adaptive designs were slightly more flexible than the neutral composite, and the assumption of rigidity for the aluminum blades was shown to be an acceptable approximation. 


\subsection{Dynamic Blade Loads}

To investigate the performance behavior of the adaptive blades as compared to the non-adaptive and rigid designs, forces and moments on the key blade of each turbine system were recorded during dynamic testing. A 30-second sample of the data output, along with the corresponding velocity measurements, is shown in Fig 7. This sample shows the blade forces, moments, and components of fluid velocity recorded on a neutral pitch composite blade system operating at a rotational frequency $f_{T}=2 \mathrm{rps}$ in a flow of $U_{h u b}=0.50 \mathrm{~m} / \mathrm{s}$. Similar force and moment data is gathered from the hub load cell. In the blade load cell, the $x$-direction points from the leading to the trailing edge of the blade at the $0^{\circ}$ pitch line, the $y$-direction points upstream, and the $z$-direction points out radially along the blade. The coordinate systems for both load cells can also be found in Fig. 3. The $x$-direction of the ADV is oriented upstream and the $y$ - and $z$-directions reflect horizontal and vertical velocities, respectively. 


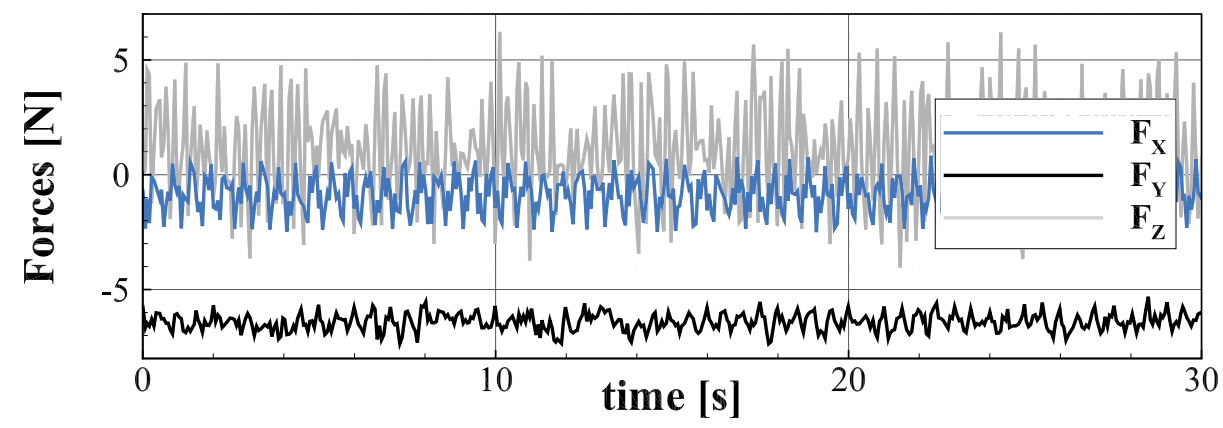

(a) Raw key blade load cell data: Blade forces.

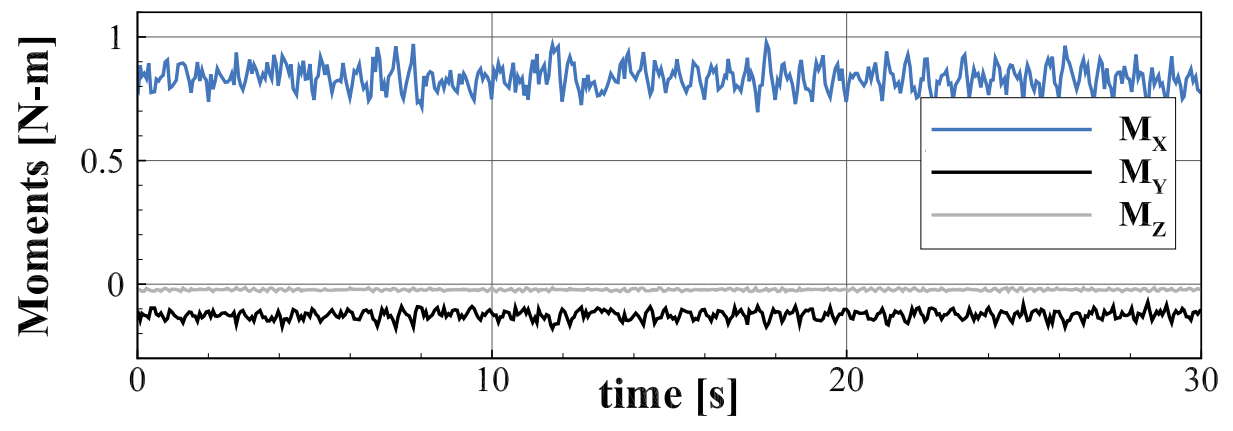

(b) Raw key blade load cell data: Blade moments.

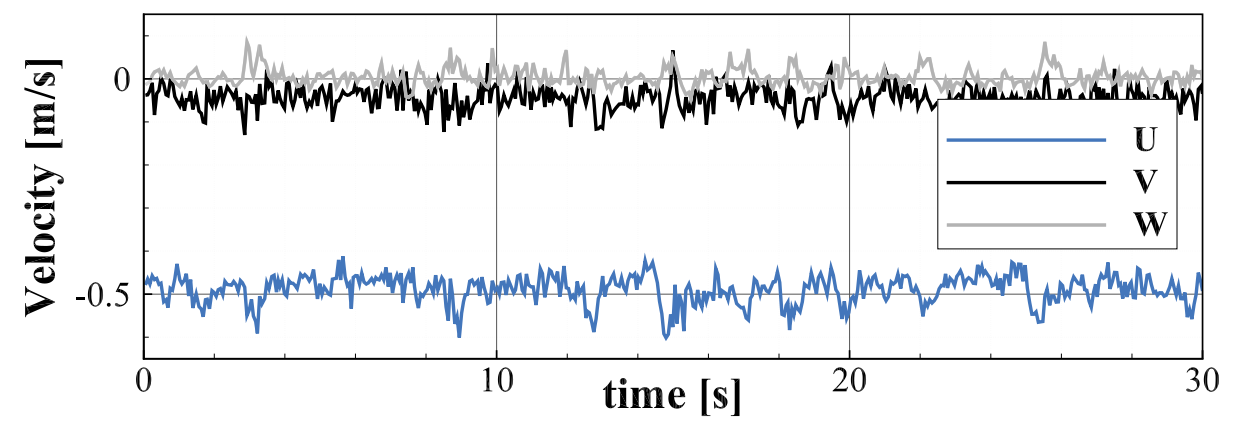

(c) Raw ADV data: Velocity.

Figure 7: Data samples from the blade load cell and ADV for the neutral pitch blades at $U_{h u b}=0.50 \mathrm{~m} / \mathrm{s}, f_{T}=2.0 \mathrm{rev} / \mathrm{s}$. Refer to the coordinate system shown in Fig. 3.

Using data from the blade load cell and ADV, it is possible to calculate 
the mean forces and moments on the key blade as a function of tip speed ratio $\left(\lambda=R \omega / U_{\text {avg }}\right)$ for each inflow velocity. These trends for all four blade designs are shown in Fig. 8 for the tests run at $U_{h u b}=0.50 \mathrm{~m} / \mathrm{s}$. The first item to notice in these figures is that the neutral pitch (non-adaptive) composite blade and the aluminum blade perform similarly in nearly all respects. The only significant difference between the two is in the z-direction force, shown in Fig. 8(a). This is effectively the centripetal force, which is larger in magnitude for the aluminum blades due to their higher total mass; the general increase in this force corresponds to the increase in rotational velocity. Beyond $B F_{Z}$, all four blade designs trend together in the x-direction forces and moments and the y-direction moments. It is worth noting that the blade pitching moment $\left(B M_{Z}\right)$ is essentially zero for all blades. This indicates that any twist the blades experience will likely be due to the bend-twist mechanism, rather than any outside forcing.

The largest difference by far between designs can be seen in the y-direction, or streamwise, forces (Fig. 8(a)) and the x-direction, or bending, moments (Fig. 8(b)). These streamwise forces and the associated bending moments are the main driver for the load-dependent adaptive pitch mechanism. Thus, at low tip speed ratios the blades experience similar loading conditions, but as the forces on the system increase the performance of the different blade designs begin to diverge. As noted above, the neutral and aluminum blades behave in a similar manner, providing a baseline model for comparison. The difference in forces and moments on the adaptive blade designs is attributable to the predicted twist deformations. Under increased load, the pitch to stall blade will twist to decrease the pitch angle, effectively increasing the angle 
of attack. This was shown statically in Fig. 5(b) as well as predicted numerically in [1]. The increase in angle of attack in turn causes the higher forces and moments seen in Fig. 8. In the opposite fashion, the pitch to feather blade twists to decrease the angle of attack and starts to shed excess loads, resulting in a reduced rate of increase in the forces and moments. 


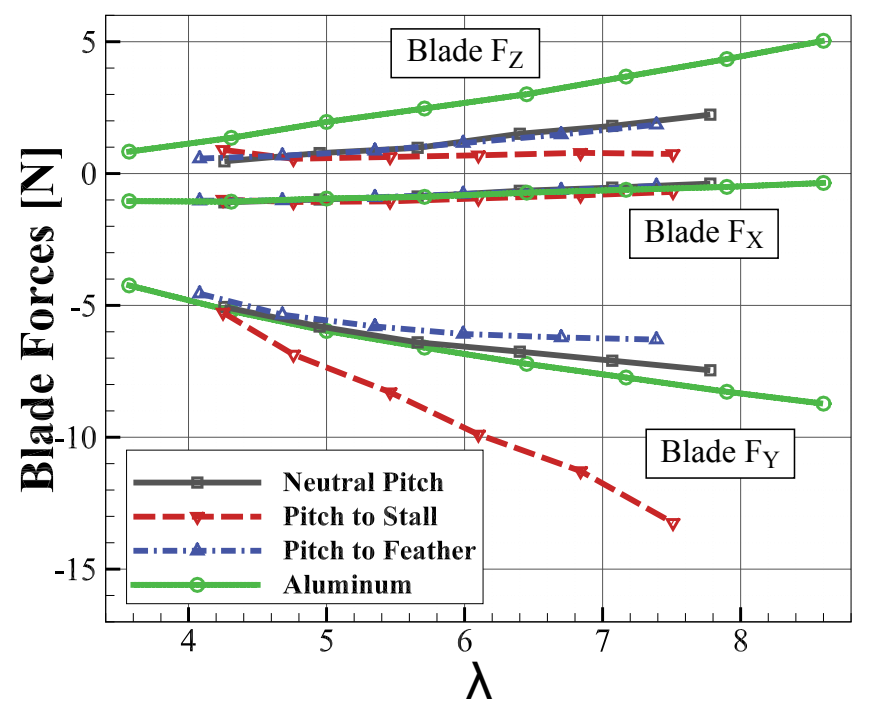

(a) Average forces on the key blade at $U_{h u b}=0.50 \mathrm{~m} / \mathrm{s}$.

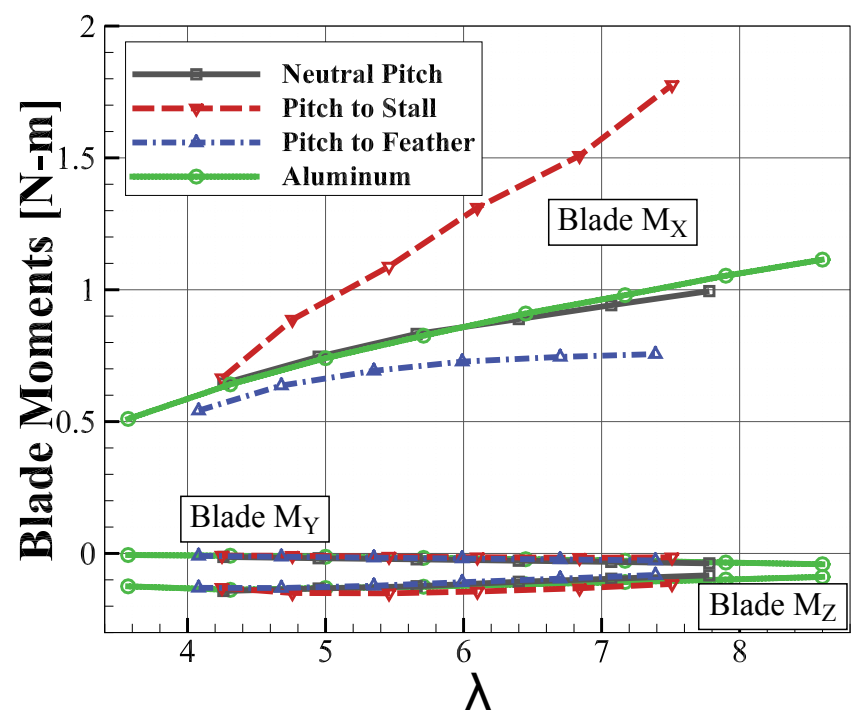

(b) Average moments on the key blade at $U_{h u b}=0.50 \mathrm{~m} / \mathrm{s}$.

Figure 8: Blade load cell measurements with increasing $\lambda$ at $U_{h u b}=0.50 \mathrm{~m} / \mathrm{s}$. 
To investigate the blade response to increased dimensional loading, each set of blades was tested over the same range of tip speed ratios at several inflow velocities. The resulting blade streamwise forces $\left(B F_{Y}\right)$ and bending moments $\left(B M_{X}\right)$ for each velocity tested are shown in Figs. 9 and 10, respectively. As the velocity increases, the forces and moments at a given tip speed ratio also increases. This underlines the necessity of taking full dimensional loading into account when assessing the performance of adaptive blades, rather than expressing performance as a simple function of tip speed ratio.

In Figs. 9 and 10, the trends noted in Fig. 8 and shown again for comparison in Figs. 9(a) and 10(a) continue to appear as velocity increases. At $U_{h u b}=0.65 \mathrm{~m} / \mathrm{s}$ (Figs. 9(b) and 10(b)) and low tip speed ratios, the composite blades show nearly identical performance which diverges as the rotational speed increases. Moreover, the change in performance in the feathering blade levels out at higher tip speed ratios, while the pitch to stall design starts to increase loading exponentially. This can be attributed to the load-dependent nature of the adaptive deformations; the pitch to feather blade twists to shed the excess loading that would cause a greater increase in twist, while the pitch to stall blade is approaching divergent behavior. It is interesting to note as well that while the forces and moments on the neutral pitch composite blade increase in a linear fashion at $U_{h u b}=0.50 \mathrm{~m} / \mathrm{s}$ and for low tip speed ratios at $U_{h u b}=0.65 \mathrm{~m} / \mathrm{s}$, this trend also starts to flatten out as loads increase. This is likely due to the slight geometric bias to pitch to feather seen in the static testing (Fig. 6). The aluminum blades were not tested at this inflow velocity. 
At $U_{h u b}=0.85 \mathrm{~m} / \mathrm{s}$, shown in Figs. $9(\mathrm{c})$ and $10(\mathrm{c})$, there is a strong difference in the loading on the various blade designs. Again, the neutral pitch and aluminum blades show comparable performance, with both blade designs indicating signs of a geometric bias to feather. The composite pitch to feather blade shows drastically decreased forces and moments, while the pitch to stall blade experienced an increase in loading to the extent that the blades failed during testing at $f_{T}=3.75 \operatorname{rps}(\lambda \approx 6.25)$. This failure was catastrophic; all three blades broke off just above the root connection within seconds of the initial failure. Further analysis of the blades showed that the failure was in the connection between the blade spar and the root-to-hub adapter, thus likely a flaw in the manufacturing process exacerbated by the higher loads on the pitch to stall system. 


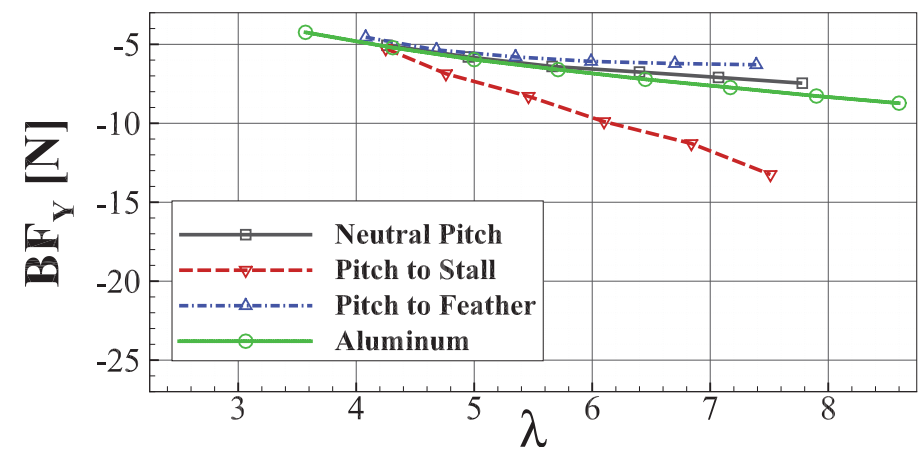

(a) Measured $B F_{Y}$ at $U_{h u b}=0.50 \mathrm{~m} / \mathrm{s}$.

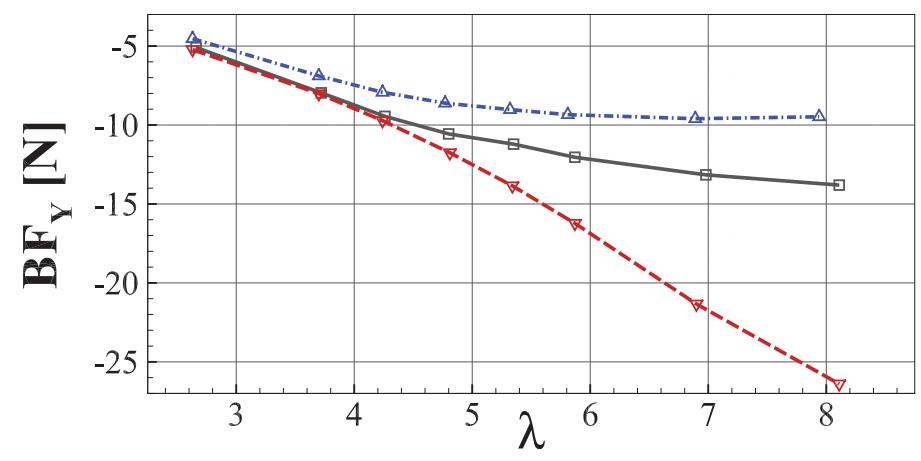

(b) Measured $B F_{Y}$ at $U_{h u b}=0.65 \mathrm{~m} / \mathrm{s}$.

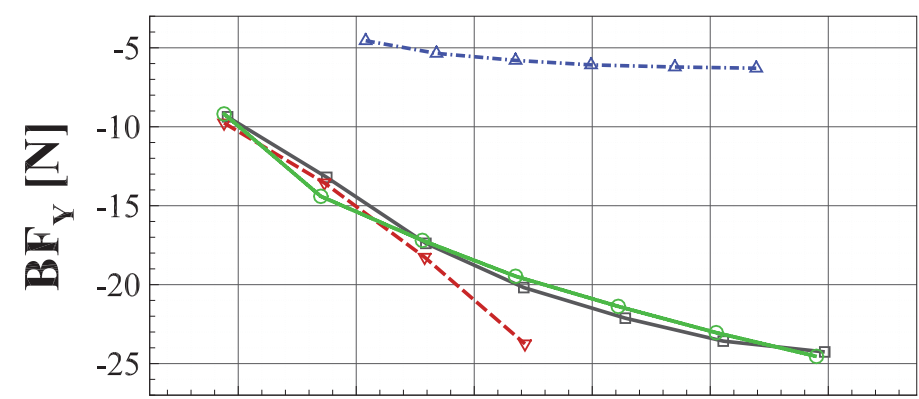

(c) Measured $B F_{Y}$ at $U_{h u b}=0.85 \mathrm{~m} / \mathrm{s}$.

Figure 9: Average streamwise forces $\left(B F_{Y}\right)$ on the blade load cell at $U_{h u b}=0.50 \mathrm{~m} / \mathrm{s}$, $0.65 \mathrm{~m} / \mathrm{s}$, and $0.85 \mathrm{~m} / \mathrm{s}$. 


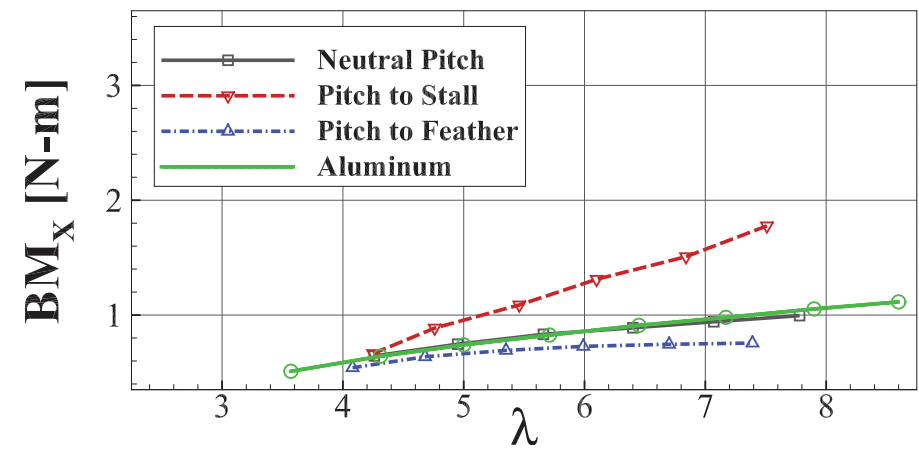

(a) Measured $B M_{X}$ at $U_{h u b}=0.50 \mathrm{~m} / \mathrm{s}$.

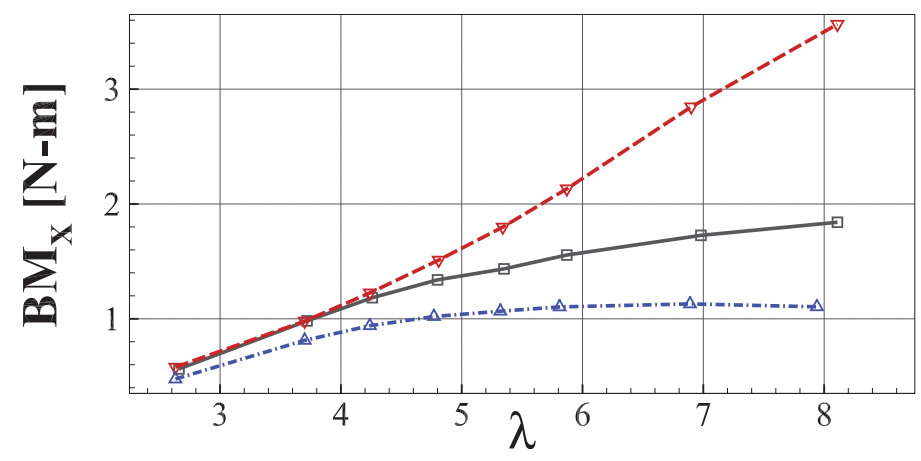

(b) Measured $B M_{X}$ at $U_{h u b}=0.65 \mathrm{~m} / \mathrm{s}$.

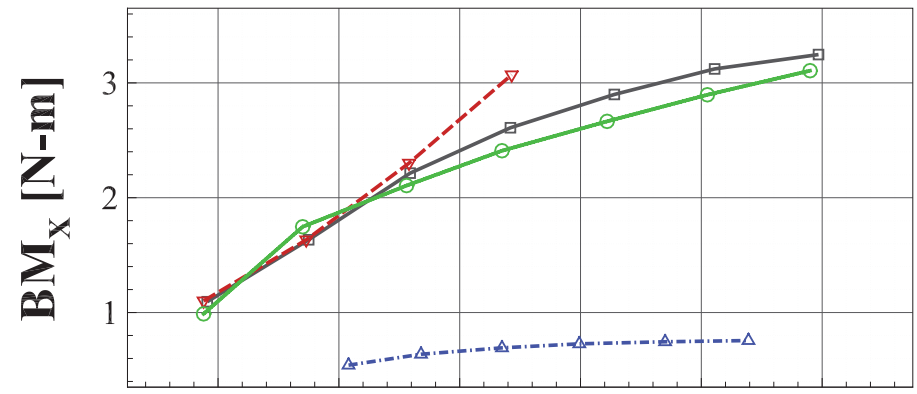

(c) Measured $B M_{X}$ at $U_{h u b}=0.85 \mathrm{~m} / \mathrm{s}$.

Figure 10: Average bending moments $\left(B M_{X}\right)$ on the blade load cell at $U_{h u b}=0.50 \mathrm{~m} / \mathrm{s}$, $0.65 \mathrm{~m} / \mathrm{s}$, and $0.85 \mathrm{~m} / \mathrm{s}$. 


\subsection{Dynamic Turbine Performance}

Along with blade loads, rotor force and moment measurements were collected. Turbine performance is commonly characterized in terms of power and thrust coefficients; to that end, the instantaneous axial thrust (T), moment $(\tau)$, velocity $\left(U_{h u b}\right)$, and angular velocity $\left(\omega=2 \pi f_{T}\right)$ measurements were used to calculate the system thrust coefficient, $C_{T}=T /\left(0.5 \rho A_{T} U_{h u b}^{2}\right)$, and power coefficient, $C_{P}=(\tau \omega) /\left(0.5 \rho A_{T} U_{h u b}^{3}\right)$ for all four blade designs. It is important to note that no blockage corrections have been applied to these data; the blockage ratio $\left(A_{T} / A_{f}\right.$, where $A_{f}$ is the cross sectional area of the flow) of the experimental setup was determined to be $\approx 22 \%$. The resulting performance curves, calculated from the tests conducted at $U_{h u b}=0.50 \mathrm{~m} / \mathrm{s}$, are shown in Fig. 11. Error bars are used to indicate the $95 \%$ confidence interval of this data. The larger error bars seen on the calculated power coefficients relative to the thrust coefficients are likely due to the slightly higher accuracy of the hub load cell in reading thrust as compared to torque measurements.

The thrust coefficients, in Fig. 11(a), generally reflect the individual blade trends seen in Fig. 9. The pitch to stall system experiences increased thrust compared to the neutral pitch design as the tip speed ratio increases, while the pitch to feather system sheds load over the same range. The neutral pitch system differs slightly from the aluminum blades, but maintains a similar trend. In Fig. 11(b), the calculated power coefficients are displayed. Though all four designs show comparable performance behavior, there are several features to highlight. From the lower tip speed ratios to the apex of the curve, the pitch to stall blade produced a generally higher $C_{P}$ than the other 
designs. The pitch to feather blade had the lowest calculated value, while the neutral and aluminum blades fell in between. However, at higher tip speed ratios, the performance of all three composite blades falls off much more steeply than the aluminum blades. This is likely due to the fact that the composite blades, especially of the pitch to stall design, showed considerable out-of-plane deformation with increased trust on the system. In this case, increased lift on the foils will not translate as directly to increased torque on the system, and much of the gains in performance expected from the pitch to stall system would be lost.

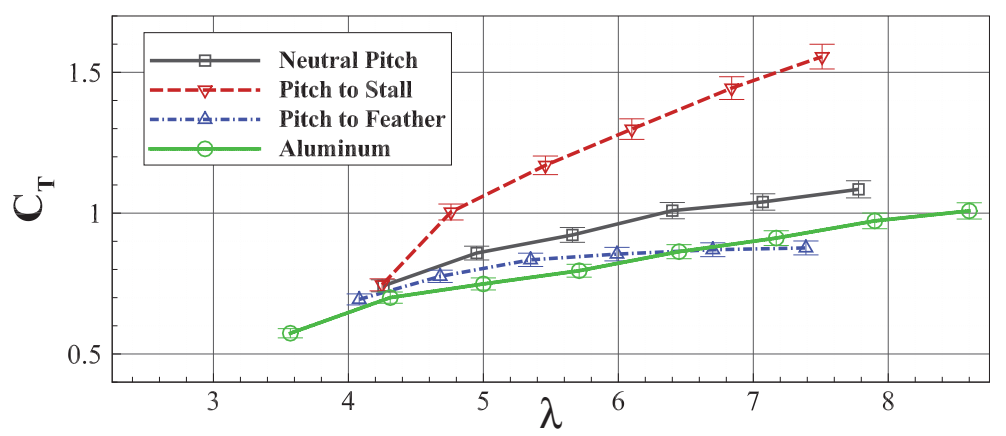

(a) Calculated thrust coefficients at $U_{h u b}=0.50 \mathrm{~m} / \mathrm{s}$.

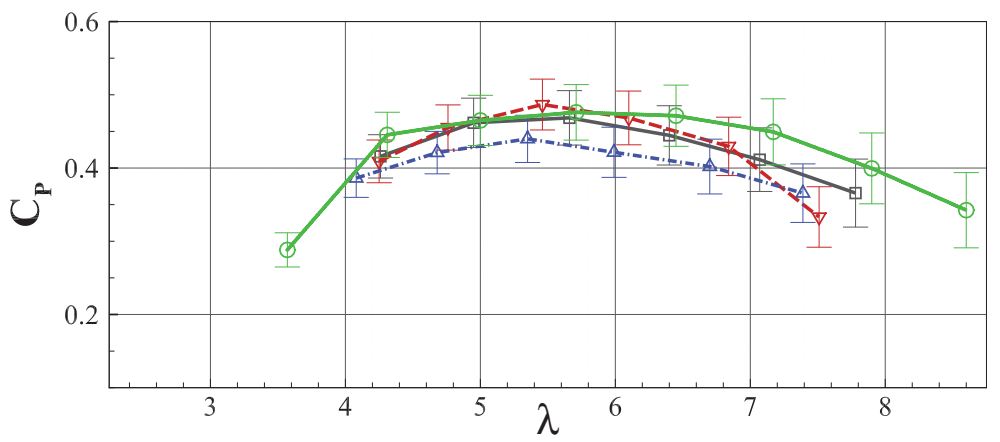

(b) Calculated power coefficients at $U_{h u b}=0.50 \mathrm{~m} / \mathrm{s}$.

Figure 11: System performance characteristics with increasing $\lambda$ at $U_{h u b}=0.50 \mathrm{~m} / \mathrm{s}$. 
As mentioned above, the adaptive composite mechanism depends on both the dimensional loading and the tip speed ratio. It is therefore essential to look at performance trends at multiple inflow velocities. To that end, Fig. 12 shows power and thrust coefficients calculated from experiments at $U_{h u b}$ $=0.85 \mathrm{~m} / \mathrm{s}$. It is interesting to note that the total uncertainty of the power coefficients at $U_{h u b}=0.85 \mathrm{~m} / \mathrm{s}$ is less than that of the power coefficients at $U_{h u b}=0.50 \mathrm{~m} / \mathrm{s}$. This is due to the fact that at the lower inflow velocity, the load cell was reading at the bottom of its calibrated range. Thus the uncertainty of the reading was a larger percentage of the measured value than it was for the higher loads measured at the higher inflow velocity.

The first aspect to note is that from $U_{h u b}=0.50 \mathrm{~m} / \mathrm{s}$ to $U_{h u b}=0.85 \mathrm{~m} / \mathrm{s}$, there is a change in the performance curves for the effectively rigid aluminum system. This indicates that Reynolds number independence was not achieved between these two runs (though data from the aluminum blades at $U_{h u b}$ $=1.0 \mathrm{~m} / \mathrm{s}$ indicates that Reynolds independence was achieved at $U_{h u b}=$ $0.85)$; it is thus difficult to quantify the change in adaptive blade performance between the two inflow cases. However, it is still informative to compare the blades to each other. Again, good agreement is seen between the neutral and aluminum turbine systems in both thrust and power coefficients. Unlike the performance calculated at $U_{h u b}=0.50 \mathrm{~m} / \mathrm{s}$, the pitch to stall system in this higher inflow case experienced greater thrust but with greatly reduced potential for power generation; this is likely an indicator that the blades had twisted far enough to stall entirely, instead of increasing the effective angle of attack within the operational limits. It is possible that this could have been another factor leading to the failure of that system at $\lambda \approx 6.25$. Most 
interesting, however, is the performance of the pitch to feather design. The load-shedding system was able to drastically reduce the thrust on the system while maintaining a power coefficient similar to the non-adaptive designs up to the peak of the performance curve. At $\lambda=6.25$, the pitch to feather design shows a $38 \%$ reduction in thrust compared to the system with rigid aluminum blades, while the decline in power is only $7 \%$. This ability to shed excess loading while maintaining power production could be a highly desirable characteristic for a marine hydrokinetic turbine system.

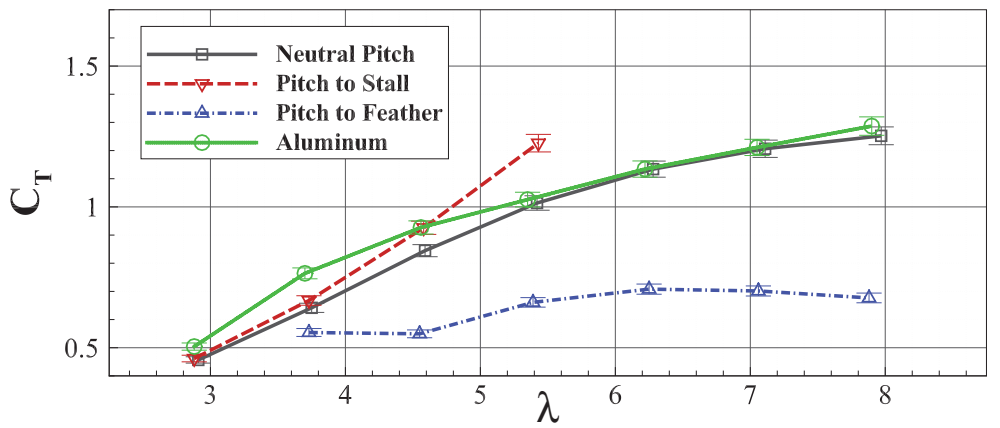

(a) Calculated thrust coefficients at $U_{h u b}=0.85 \mathrm{~m} / \mathrm{s}$.

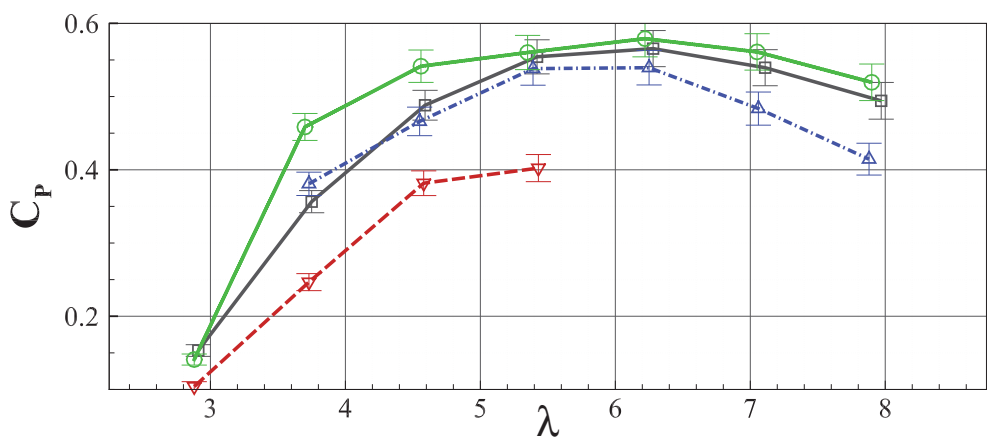

(b) Calculated power coefficients at $U_{h u b}=0.85 \mathrm{~m} / \mathrm{s}$.

Figure 12: System performance characteristics with increasing $\lambda$ at $U_{h u b}=0.85 \mathrm{~m} / \mathrm{s}$. 


\section{Conclusions}

In this work, experiments were conducted with four sets of flume-scale marine hydrokinetic turbine blades. The performance of two sets of adaptive composite blades, one designed to pitch to stall and one to pitch to feather, were compared to that of a neutral pitch blade design and an effectively rigid aluminum set under static and dynamic testing conditions.

In static load-deformation tests performed at the University of Washington, force-deflection and force-twist response were measured. Additionally, an empirical deflection-twist relationship was calculated. Though both adaptive blades behaved similarly in bending, the pitch to stall blades were found to twist to decrease blade pitch under load (which would increase effective angle of attack), while the pitch to feather design instead twisted to increase blade pitch (decreasing angle of attack). The neutral pitch blades were shown to be slightly stiffer than the adaptive designs in bending, and evidenced a slight bias towards pitching to feather under load. The assumption of rigidity for the aluminum blades was shown to be valid, though these blades also displayed a geometric pitch to feather bias.

Dynamic experiments were also performed in the flume at the Bamfield Marine Sciences Center. During these tests, instantaneous forces and moments were recorded on the turbine system and on one of the three blades during operation at varying rotational speeds and inflow velocities. Combined with the instantaneous fluid velocity measurements, these data were used to quantify blade forces and moments as a function of tip speed ratio, as well as overall system performance curves at several inflow velocities. The results of these tests show that in general, the pitch to stall blades experience 
increased forces and moments compared to the neutral pitch and aluminum blades. This translates to increased power generation at low dimensional loads, but under higher loading conditions caused excessive out of plane deformation, potential fluid stall, and blade failure. In the opposite fashion, the pitch to feather systems demonstrated lower blade loads and system thrust, with a relatively small decrease in power capture capabilities. This feature could prove a valuable asset to a marine hydrokinetic turbine system.

\section{Acknowledgments}

This work was funded by the United States Department of Defense Naval Facilities Engineering Command. Special thanks to those whose hard work and dedication made this research a success; Justin Burnett, Michelle Hickner, Noah Johnson, Brian Polagye, Andy Stewart, and Katherine Van Ness.

\section{References}

[1] M. Motley, R. Barber, Passive control of marine hydrokinetic turbine blades, Composite Structures 110 (2014) 133-139.

[2] M. Motley, R. Barber, Passive pitch control of horizontal axis marine hydrokinetic turbine blades, in: 33rd International Conference on Ocean, Offshore and Arctic Engineering, 2014.

[3] R. Barber, M. Motley, Cavitating response of passively controlled tidal turbines, Journal of Fluids and Structures 66 (2016) 462-475.

[4] R. Barber, M. Motley, A numerical study of the effect of passive control 
on cavitation for marine hydrokinetic turbines, in: European Wave and Tidal Energy Conference, Nantes, France, 2015.

[5] R. Murray, K. Gracie, D. Doman, M. Pegg, C. Johnstone, Design of a passively adaptive rotor blade for optimized performance of a horizontalaxis tidal turbine, in: 10th European Wave and Tidal Energy Conference, Aalborg, Denmark, 2013.

[6] R. Nicholls-Lee, S. Turnock, S. Boyd, Application of bend-twist coupled blades for horizontal axis tidal turbines, Renewable Energy 50 (2013) $541-550$.

[7] Y. Young, M. Motley, R. Barber, E. Chae, N. Garg, Adaptive composite marine propulsors and turbines: progress and challenges, Applied Mechanics Reviews 38 (2011) 1368-1381.

[8] Y. Lee, C. Lin, Optimized design of composite propeller, Mechanics of Advanced Materials and Structures 11 (2004) 17-30.

[9] C. Lin, Y. Lee, Stacking sequence optimization of laminated composite structures using genetic algorithm with local improvement, Composite Structures 63 (2004) 339-345.

[10] C. Lin, Y. Lee, C. Hung, Optimization and experiment of composite marine propellers, Composite Structures 89 (2009) 206-215.

[11] Y. Young, Z. Liu, Performance prediction of Newton-Rader propellers, Journal of Ship Research 52 (2). 
[12] Y. Young, Z. Liu, M. Motley, Influence of material anisotropy on the hydroelastic behaviors of composite marine propellers, in: ONR NH Symposium on Naval Hydrodynamics, 2008.

[13] A. Beyene, J. Peffley, Constructual theory, adaptive motion, and their theoretical application to low-speed turbine design, Journal of Energy Engineering (2009) 112-118.

[14] P. Jeffcoate, R. Starzmann, B. Elsaesser, S. Scholl, S. Bischoff, Field measurements of a full scale tidal turbine, International Journal of Marine Energy.

[15] R. Starzmann, M. Baldus, E. Groh, N. Hirsch, N. Lange, S. Scholl, A stepwise approach towards the development and full-scale testing of a marine hydrokinetic turbine, in: 1st Marine Energy Technology Symposium, Washington, D.C., 2013.

[16] R. Starzmann, P. Jeffcaote, S. Scholl, S. Bischoff, B. Elsaesser, Field testing a full-scale tidal turbine, in: 11th European Wave and Tidal Energy Conference, Nantes, France, 2015.

[17] B. Polagye, J. Thomson, Tidal energy resource characterization: methodology and field study in admiralty inlet, puget sound, us, Proceedings of the Institution of Mechanical Engineers, Part A: Journal of Power and Energy 227 (3) (2013) 352-367.

[18] ABAQUS, ABAQUS Version 12.3 Documentation, ABAQUS, Inc. (2012). 
[19] R. Dieck, W. Steele, G. Osolsobe, Test uncertainty, in: ASME PTC 19.1-2005, American Society of Mechanical Engineers, New York, NY, 2005. 